\title{
Rancang Purwarupa Aplikasi Becakap Bagi Masyarakat Pesisir dengan Pendekatan Design Thinking
}

\author{
Steffi Adam ${ }^{1 *}$, Suryo Widiantoro ${ }^{2 *}$ \\ * Sistem Informasi, Universitas Universal \\ steffiadam.ssi@gmail.com ${ }^{1}$, suryo.widiantoro@gmail.com $^{1}$
}

\begin{tabular}{l} 
Article Info \\
\hline Article history: \\
Received 2019-11-19 \\
Revised 2019-11-22 \\
Accepted 2019-11-26 \\
\hline
\end{tabular}

Keyword:

Design Thinking, Information Technology, Inovation,

Human Centered Design, Coastal Community.

\begin{abstract}
The purpose of this study is to design an application prototype that can help the distribution of information for coastal communities. The Riau Islands Province Medium Term Regional Development Plan 2016-2021 explains that investment opportunities in the Riau Islands begin to penetrate the coastal areas. The Batam City Government is try to ensure equitable development through access to information technology, but coastal communities still have difficulty utilizing the information technology. This research is a qualitative research with a Design Thinking approach. The Design Thinking approach has five stages namely emphatize, define, ideate, prototype, test, and implement. Design Thinking Approach is an approach used to create innovation by focusing on "Human Centered Design". Data collection methods that will be used in this study are observation and interviews. The results of this study are the Becakap Prototype application which has four functions, namely scholarship information, sea level information, weather information, and for action. This application makes it easy for coastal communities to access the information needed.
\end{abstract}

Copyright (C) 2019 Journal of Applied Informatics and Computing. All rights reserved.

\section{Pendahuluan}

Inovasi dan teknologi berkembang pesat. Para ahli menyebut perkembangan teknologi dan inovasi ini dengan revolusi komunikasi [1]. Perkembangan teknologi dan inovasi ini diharapkan mampu memberikan kemudahan bagi manusia dalam melakukan pekerjaannya. Selain itu, juga membantu manusia menyelesaikan permasalahan yang ada. Inovasi diperlukan untuk menciptakan kesempatan yang baik dan juga merancang sebuah produk pelayanan yang sesuai dengan kebutuhan manusia. Begitu pula, inovasi teknologi yang secara sederhana dapat diartikan sebagai suatu cara mencari kesempatan yang baik dan memanfaatkannya [2]. Adanya inovasi, maka teknologi yang berkembang dapat diserap dan dimanfaatkan untuk kebutuhan manusia.

Pada perkembangannya, inovasi di bidang teknologi informasi yang berkembang saat ini cenderung berfokus pada fungsi dan tampilan produk yang dihasilkan [1] [3]. Banyak produk memiliki tampilan menarik untuk memikat penggunanya. Selain itu juga fungsi-fungsi yang semakin canggih juga selalu dihadirkan pada produk teknologi terkini. Sayangnya, hal ini menyebabkan produk inovasi yang dihasilkan unggul dalam produk namun kurang maksimal dalam menyelesaikan masalah yang terjadi di masyarakat.
Kota Batam memiliki wilayah yang strategis karena berbatasan langsung dengan Negara Singapura. Hal ini menyebabkan Kota Batam tumbuh dan berkembang dengan pesat. Sayangnya, pertumbuhan Kota Batam tidak diiringi dengan pemerataan pembangunan bagi masyarakatnya [4] Banyak masyarakat pesisir yang termarginalkan dikarenakan menetap pada pulau-pulau yang letaknya berjauhan dengan pusat kota. Dalam RPJMD Provinsi Kepulauan Riau Tahun 2016-2021 dijelaskan bahwa pemodal berpeluang menenamkan investasinya di Provinsi Kepulauan Riau dalam mengembangkan sumberdaya perikanan yang sangat besar menjadi peluang bagi pengembangan industri pengolahan produk perikanan yang berdaya saing tinggi, termasuk dalam pengembangan pariwisata pantai, laut dan pulau-pulau kecil. Untuk mendukung hal tersebut, maka masyarakat pesisir juga harus dikembangkan dan mendapat informasi yang sama dalam pembangunan. Pemerintah Kota Batam berusaha agar masyarakat dapat mengakses informasi tersebut dengan bantuan teknologi informasi. Melalui teknologi informasi diharapkan masyarakat pesisir dapat mengakses teknologi seperti aplikasi ataupun website agar tidak ketinggalan informasi [5] [6]. Sehingga pemerataan pembangunan tetap terjadi. Sayangnya, meskipun di beberapa wilayah telah didukung oleh akses internet yang memadai, namun pemanfaatan teknologi informasi masih kurang maksimal. 
Menurut survey pra penelitian yang dilakukan peneliti, ditemukan bahwa akses internet yang mudah kurang maksimal dalam penggunaannya. Masyarakat cenderung mengabaikan keberadaan teknologi informasi tersebut.

Pendekatan design thinking merupakan suatu pendekatan yang digunakan untuk menciptakan inovasi dengan berfokus pada "Human Centered Design" atau bisa juga disebut "User Centered Design" [7]. Selain itu, Design thinking merujuk pada tiga factor kesuksesan inovasi yaitu desirability, feasibility, dan viability [8]. Design thinking juga mengkolaborasikan sisi teori keilmuan dan kondisi manusia sebagai pusat inovasi. Dapat dikatakan, pendekatan design thinking menitikberatkan manusia sebagai pusat inovasi [1], [7]-[10].

Penelitian ini menitikberatkan pada pendekatan design thinking sebagai metode untuk menghasilkan inovasi teknologi informasi yang berfokus pada "Human Centered Design". Pendekatan design thinking ini baru populer digunakan dalam inovasi teknologi informasi [8], [11], namun sudah lebih populer dalam inovasi dalam sebuah organisasi dan inovasi sosial [9][10][12][13]. Design thinking umumnya didefinisikan sebagai proses analitik dan kreatif itu melibatkan seseorang dalam peluang untuk bereksperimen, membuat dan model prototipe, mengumpulkan umpan balik, dan mendesain ulang. Beberapa karakteristik (misalnya, visualisasi, kreativitas) yang harus dimiliki oleh seorang pemikir desain yang baik telah diidentifikasi dari literatur. Tujuan utama dari artikel ini adalah untuk meringkas dan mensintesis penelitian tentang pemikiran desain untuk lebih memahami karakteristiknya dan proses, serta perbedaan antara pemula dan pemikir ahli desain, dan menerapkan temuan dari literatur tentang penerapan pemikiran desain untuk sistem pendidikan kita Tujuan menyeluruh adalah untuk mengidentifikasi fitur dan karakteristik desain berpikir dan diskusikan pentingnya dalam mempromosikan pemecahan masalah [14].

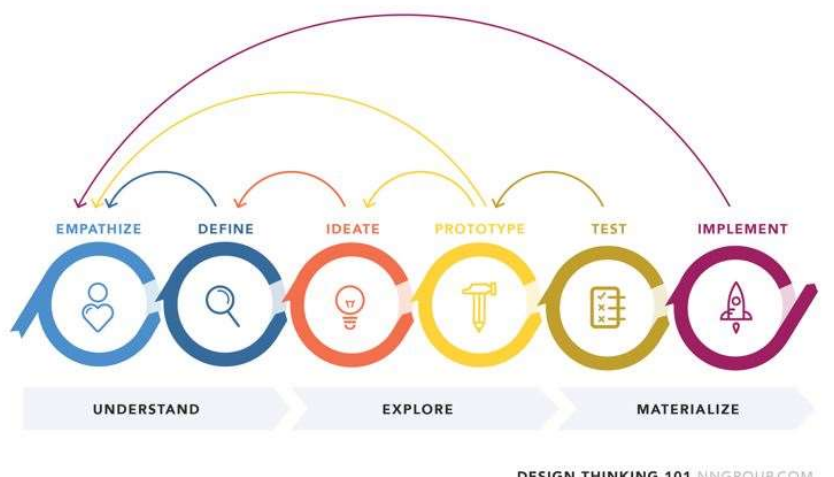

Sumber: https://www.nngroup.com/articles/design-thinking/

Gambar 1. Kerangka Design Thinking

Design thinking merupakan sebuah metode pendekatan proses desain yang untuk mencari solusi dalam memecahkan masalah. Metode ini banyak memengaruhi cara pengambilan keputusan yang akhirnya menghasilkan ide-ide baru dan inovatif. Penelitian yang dilakukan Universitas Islam Indonesia menggunakan design thinking untuk menemukan solusi untuk masalah perpusatakaan di kampus tersebut. Metode pengambilan data yang digunakan, sebelum proses pembuatan prototype adalah wawancara dan observasi terhadap pengguna, juga studi kepustakaan. Pendekatan design thinking mengedepankan aspek user centered design. Penelitian tersebut menghasilkan mobile application UniBook yang membantu dan memudahkan mahasiswa dalam berbagai aktivitas pinjam-meminjam di Perpustakaan Pusat Universitas Islam Indonesia [1].

Penelitian lain juga sebelumnya telah dilakukan oleh O'Driscoll dengan metode studi kepustakaan juga menemukan bahwa penggunaan design thinking dikolaborasikan dengan agile method, digunakan untuk mengembangkan suatu teknologi informasi. Hasil penelitian menemukan bahwa penerapan design thinking digunakan untuk membantu pengembangan teknologi informasi yang berkaitan dengan faktor non teknis seperti manusia dan budaya organisasi, dimana faktor non teknis lebih penting daripada faktor teknis dalam pengembangan suatu teknologi informasi [11].

Selanjutnya penelitian membahas mengenai penggunaan design thinking dalam proyek sistem informasi dengan metode studi kepustakaan menemukan bahwa design thinking teruji dan terbukti berhasil memberikan kontribusi yang signifikan pada penelitian di bidang sistem informasi. Design thinking sebagai metode dan alat yang berorientasi pada praktek memudahkan para akademisi dan peneliti untuk menggali sisi teoritis suatu bidang keilmuan dan juga sisi psikologis. Design thinking juga mempermudah penelusuran dan pemahaman tentang proses kreatif serta meningkatkan kredibilitas hasil yang dicapai. Design thiniking juga berkontribusi pada temuan-temuan baru selama penelitian yang juga memanfaatkan kontribusi pengetahuan. Kesimpulan yang diperoleh bahwa design thinking berkontribusi dan dapat digunakan pada penelitian proyek sistem informasi [8].

Design thinking telah menunjukkan potensinya untuk menghasilkan inovatif, dengan konsep user centered design dan banyak digunakan oleh konsultan seperti IDEO. Integrasi yang benar dari proses design thinking dapat menghasilkan pengembangan perangkat lunak dengan ide-ide yang kreatif dan menjadi produk nyata. Kesimpulan dari penelitian yang dilakukan adalah intergrasi dari design thinking menghasilkan sebuah outline apikasi masa depan di Dt@scrum [15].

\section{METODE PENELITIAN}

Penelitian ini merupakan penelitian kualitatif dengan pendekatan Design Thinking. 


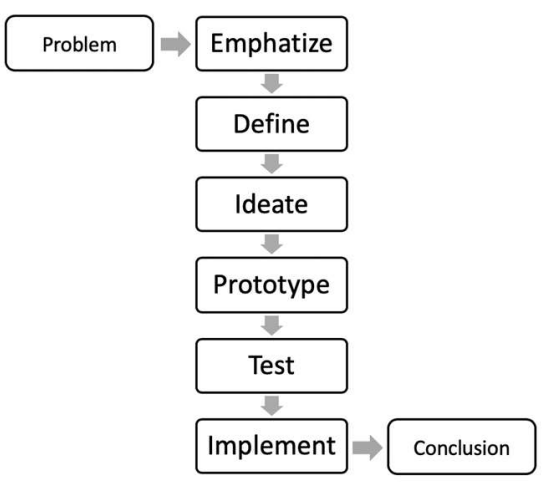

Gambar 2. Metode Penelitian

Gambar 2 menjelaskan tahapan-tahapan yang dilakukan pada penelitian ini disesuaikan dengan tahapan pada metode design thinking.

\section{Problem}

Masalah yang diangkat dalam penelitian ini adalah ketidakmerataan informasi yang didapat oleh masyarakat pesisir. Penelitian ini bertujuan untuk merancang prototype aplikasi yang dapat membantu pemerataan informasi bagi masyarakat pesisir.

\section{Tahapan Emphatize}

Tahapan Emphatize dalam design thinking dilakukan untuk menangkap masalah yang sebenarnya terjadi pada objek penelitian. Tahapan ini juga mengajak peneliti untuk melihat permasalahan dari sisi masyarakat yang diteliti. Dalam penelitian ini, pengumpulan data pada tahapan emphatize dilakukan dengan metode observasi dan wawancara.

Observasi dilakukan oleh tim peneliti dengan cara mengunjungi langsung objek penelitian dan ikut berpartisipasi dalam kegiatan yang melibatkan pemanfaatan teknologi informasi bagi masyarakat pesisir. Observasi dilakukan selama 2 hari di masing-masing pulau.

Wawancara dilakukan oleh tim peneliti untuk menggali informasi yang didapatkan selama observasi dan juga memperkuat temuan-temuan yang didapat oleh peneliti. Narasumber dari wawancara ini memiliki kriteria sebagai penduduk asli pulau yang tergolong masyarakat pesisir dan aktif menggunakan teknologi informasi dalam keseharian.

Observasi dan wawancara yang dilakukan berfokus pada persoalan (1) jenis teknologi informasi yang biasa digunakan masyarakat, (2) kebiasaan, tujuan, motivasi penggunaan teknologi informasi, (3) faktor penyebab keengganan menggunakan teknologi informasi, (4) kebiasaan, adat istiadat, budaya, dan catatan lain yang mendukung pemerataan informasi.

Pada penelitian ini peneliti mengambil data dari masyarakat pesisir yang berada di daerah Kecamatan Belakang Padang. Observasi dan wawancara dilakukan di empat pulau yaitu; Pulau Belakang Padang, Pulau Lengkang, Pulau Sarang, dan Pulau Mecan.

\section{Tahapan Define}

Tahapan define dilakukan setelah mendapatkan data dari tahapan sebelumnya yaitu tahapan emphatize. Pada tahapan ini tim peneliti berdiskusi untuk menemukan kebutuhan dominan dari masyarakat pesisir. Metode yang digunakan pada tahapan ini adalah brainstorming.

\section{Tahapan Ideate}

Brainstroming pada tahapan define, dilanjutkan untuk menrincikan kebutuhan dari masyarakat pesisir pada tahapan ideate. Perincian ini dilakukan secara mendalam dengan memperhatikan kebiasaan, budaya, maupun hal-hal yang biasa dilakukan oleh masyarakat pesisir.

\section{Tahapan Prototype}

Prototype pada penelitian ini dilakukan dengan membuat use case diagram untuk sistem yang akan dirancang, selanjutnya dibangun aplikasi versi beta untuk diujicobakan.

\section{Tahapan Test dan Implement}

Tahapan Test dan Implement pada penelitian ini dilakukan secara bersamaan. Setelah versi beta selesai dibangun, ujicoba pertama dilakukan oleh tim peneliti.

\section{Conclusion}

Penelitian ini diakhiri dengan menarik kesimpulan dari proses penelitian yang telah dilaksanakan.

\section{HASIL DAN PEMBAHASAN}

Hasil penelitian mengungkap hasil temuan yang diperoleh pada tahapan-tahapan metode penelitian sebagai berikut.

\section{Tahapan Emphatize}

Tahapan Emphatize dilakukan dengan metode Wawancara dan Observasi. Observasi dilakukan di empat pulau dengan durasi observasi selama 2 hari per pulau. Total waktu yang dibutuhkan untuk observasi adalah 8 hari. Wawancara dilakukan kepada empat orang narasumber yang tersebar di masing-masing pulau. Adapun profil narasumber dapat dilihat di tabel I.

TABEL I

PROFIL NARASUMBER

\begin{tabular}{|l|l|l|l|}
\hline \multicolumn{1}{|c|}{ Lokasi } & Jenis Kelamin & \multicolumn{1}{c|}{ Usia } & \multicolumn{1}{c|}{ Pekerjaan } \\
\hline $\begin{array}{l}\text { P. Belakang } \\
\text { Padang }\end{array}$ & Perempuan & 24 tahun & Karyawan \\
\hline P. Lengkang & Laki-Laki & 23 tahun & Tidak Bekerja \\
\hline P. Sarang & Laki-laki & 27 tahun & Karyawan \\
\hline P. Mecan & Laki-laki & 47 tahun & Nelayan \\
\hline
\end{tabular}

Pada penelitian ini narasumber yang dipilih sesuai dengan kriteria yang telah ditetapkan. Narasumber terdiri dari 3 lakilaki dan 1 perempuan. Usia yang mendominasi narasumber adalah berada diantara 20-30 tahun, dengan 2 orang bekerja sebagai karyawan, 1 orang tidak bekerja, dan 1 orang bekerja sebagai nelayan. Hasil wawancara dan observasi dapat dilihat pada tabel II 
TABEL II

HASIL OBSERVASI DAN WAWANCARA

\begin{tabular}{|c|c|c|c|c|}
\hline Lokasi & $\begin{array}{l}\text { Kebiasaan } \\
\text { Penggunaan } \\
\text { TI }\end{array}$ & $\begin{array}{l}\text { Jenis TI } \\
\text { yang } \\
\text { digunakan }\end{array}$ & $\begin{array}{l}\text { Faktor } \\
\text { Keengganan } \\
\text { Menggunak } \\
\text { an TI }\end{array}$ & Catatan lain \\
\hline $\begin{array}{l}\text { Belakang } \\
\text { Padang }\end{array}$ & $\begin{array}{l}\text { Mengakses } \\
\text { Media } \\
\text { Sosial; } \\
\text { Berkomunik } \\
\text { asi; Jualan } \\
\text { Online ; } \\
\text { Main Games }\end{array}$ & $\begin{array}{l}\text { Smartphone } \\
\text { Laptop }\end{array}$ & $\begin{array}{l}\text { Penyebaran } \\
\text { Berita Hoax; } \\
\text { Kurang } \\
\text { pemahaman; } \\
\text { Tidak punya } \\
\text { pulsa }\end{array}$ & $\begin{array}{l}\text { Media Sosial } \\
\text { digunakan } \\
\text { untuk sarana } \\
\text { promosi bagi } \\
\text { yang } \\
\text { berjualan }\end{array}$ \\
\hline $\begin{array}{l}\text { Pulau } \\
\text { Mecan }\end{array}$ & $\begin{array}{l}\text { Mencari } \\
\text { Tugas } \\
\text { Sekolah; } \\
\text { Sarana } \\
\text { Komunikasi }\end{array}$ & $\begin{array}{l}\text { Laptop } \\
\text { Handphone }\end{array}$ & $\begin{array}{l}\text { Sering } \\
\text { terkena } \\
\text { Roaming } \\
\text { (Karena } \\
\text { dekat } \\
\text { Singapore) }\end{array}$ & $\begin{array}{l}\text { Karena sering } \\
\text { terkena } \\
\text { roaming jadi } \\
\text { hanya } \\
\text { mengakses } \\
\text { yang penting } \\
\text { seperti untuk } \\
\text { keperluan } \\
\text { tugas sekolah }\end{array}$ \\
\hline $\begin{array}{l}\text { Pulau } \\
\text { Sarang }\end{array}$ & $\begin{array}{l}\text { Mengakses } \\
\text { Media } \\
\text { Sosial; } \\
\text { Berkomunik } \\
\text { asi }\end{array}$ & $\begin{array}{l}\text { Smartphone } \\
\text { Laptop }\end{array}$ & $\begin{array}{l}\text { Kurang } \\
\text { mengerti } \\
\text { penggunaan } \\
\text { nya; Tidak } \\
\text { ada Pulsa }\end{array}$ & $\begin{array}{l}\text { Dibutuhkan } \\
\text { informasi } \\
\text { beasiswa } \\
\text { untuk anak- } \\
\text { anak yang } \\
\text { akan sekolah } \\
\text { lanjut, para } \\
\text { nelayan } \\
\text { masih } \\
\text { menggunakan } \\
\text { perkiraan } \\
\text { cuaca yang } \\
\text { manual }\end{array}$ \\
\hline $\begin{array}{l}\text { Pulau } \\
\text { Lengkang }\end{array}$ & $\begin{array}{l}\text { Bermain } \\
\text { Game } \\
\text { Online; } \\
\text { Berkomunik } \\
\text { asi; } \\
\text { Mengerjaka } \\
\text { n tugas } \\
\text { sekolah }\end{array}$ & $\begin{array}{l}\text { Smartphone } \\
\text { dengan rata- } \\
\text { rata RAM } \\
2 \text { GB }\end{array}$ & $\begin{array}{l}\text { Kurang } \\
\text { mengerti } \\
\text { penggunaan } \\
\text { nya; Tidak } \\
\text { ada Pulsa }\end{array}$ & $\begin{array}{l}\text { Nelayan } \\
\text { kesulitan } \\
\text { mendapatkan } \\
\text { info pasang } \\
\text { surut air laut. }\end{array}$ \\
\hline
\end{tabular}

Pada tabel II terlihat bahwa smartphone merupakan teknologi informasi yang dominan digunakan oleh masyarakat pesisir. Smartphone dimanfaatkan untuk mengakses media sosial, hiburan, dan komunikasi sehari-hari. Sebagian masyarakat juga memanfaatkan laptop dan smartphone untuk mengerjakan tugas sekolah.

\section{Tahapan Define}

Pada tahapan define, peneliti mengerucutkan kebutuhankebutuhan dominan yang dibutuhkan oleh pengguna. Dari hasil yang didapatkan pada tahapan emphatize, maka peneliti memfokuskan pada kebutuhan pengguna yang berkaitan dengan informasi di bidang pendidikan, informasi bagi nelayan, dan juga informasi untuk membantu nelayan.

\section{Tahapan Ideate}

Pada tahapan Ideate, Ide-ide tersebut lebih di detailkan, dimana informasi di bidang pendidikan yaitu berkaitan dengan informasi beasiswa; kemudian informasi mengenai ramalan cuaca dan juga pasang surut air laut; serta fitur yang memungkinkan penduduk antar pulau bisa berinteraksi. Kebutuhan pengguna tersebut akan dirancang dalam bentuk aplikasi yang diberi nama Becakap. Pemilihan teknologi berupa aplikasi dikarenakan, kebanyakan masyarakat pesisir yang mengakses teknologi, lebih mudah mengakses aplikasi daripada harus membuka website. Hal ini dapat dilihat dari kebiasaan mereka ketika mengakses media sosial atau juga berkomunikasi selalu menggunakan aplikasi.

\section{Tahapan Prototype}

Tahapan Prototype dimulai dengan menggambarkan use case diagram serta mendefinisikan fungsi di dalam sistem tersebut, seperti pada gambar 2 berikut:

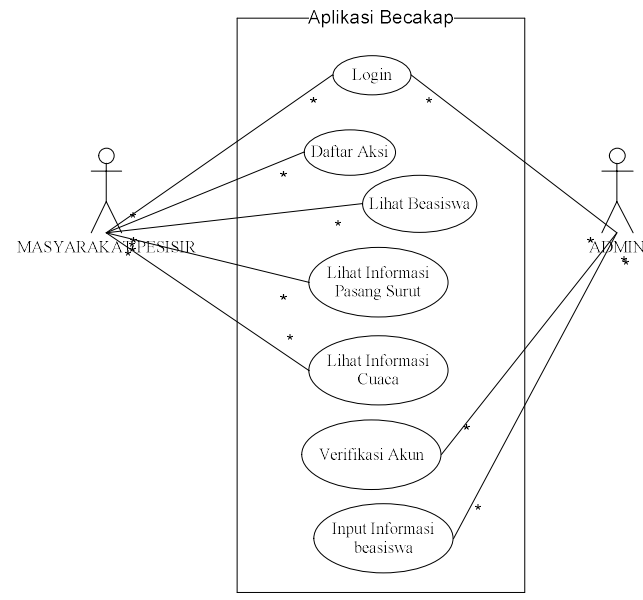

Gambar 2. Use Case Diagram

Gambar 2 menjelaskan Use Case Diagram dari sistem tersebut, dimana masyarakat pesisir dapat melakukan aktivitas yaitu Login, lihat beasiswa, lihat informasi pasang surut, lihat informasi cuaca, dan daftar aksi. Sedangkan Admin dapat melakukan aktivitas yaitu Login, Verifikasi Akun, dan Input informasi beasiswa. Berikut merupakan beberapa tampilan dari aplikasi Becakap.

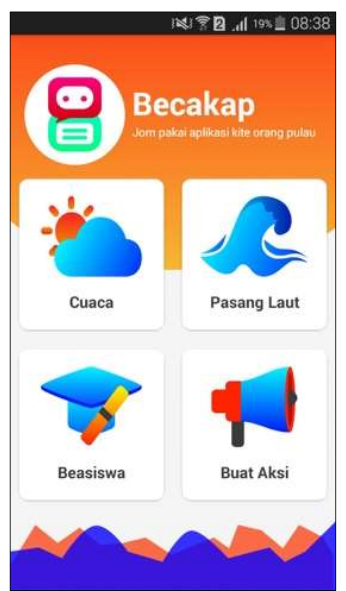

Gambar 3. Tampilan Awal Aplikasi Becakap

Gambar 3 menunjukkan pada tampilan awal aplikasi becakap, terdapat 4 menu utama yaitu: Cuaca, Pasang Laut, Beasiswa, dan Buat Aksi. Fungsi-fungsi pada aplikasi ini disesuaikan dengan hasil yang didapat pada tahapan 
emphatize. Dari hasil observasi dan wawancara ditemukan bahwa masyarakat pesissir memerlukan informasi yang berguna bagi nelayan, bagi anak-anak sekolah, dan pemuda untuk tetap saling terhubung dan berkomunikasi.

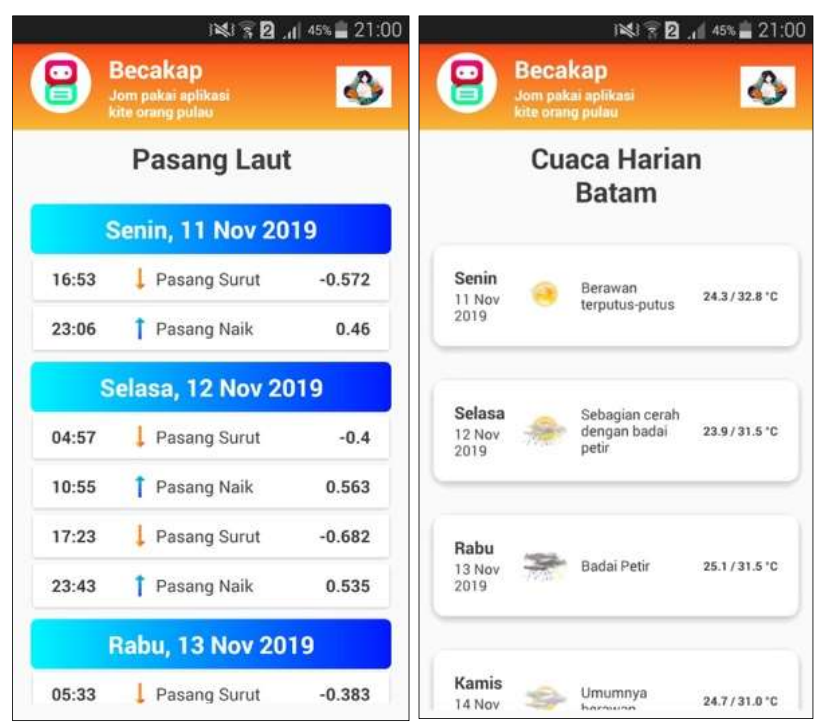

Gambar 4. Tampilan Menu Pasang Laut dan Cuaca

Gambar 4 menampilkan tampilan menu pasang laut dan cuaca, menu ini menampilkan informasi update pasang laut dan cuaca daerah sekitar pulau. Untuk memanfaatkan menu ini, pengguna tidak perlu login. Hanya perlu memilih menu tersebut. Menu pasang laut dan menu cuaca merupakan menu yang disajikan untuk membantu nelayan dalam mencari ikan. Nelayan membutuhkan informasi berkaitan dengan kedua hal tersebut, untuk mempermudah mengambil keputusan ketika melaut.

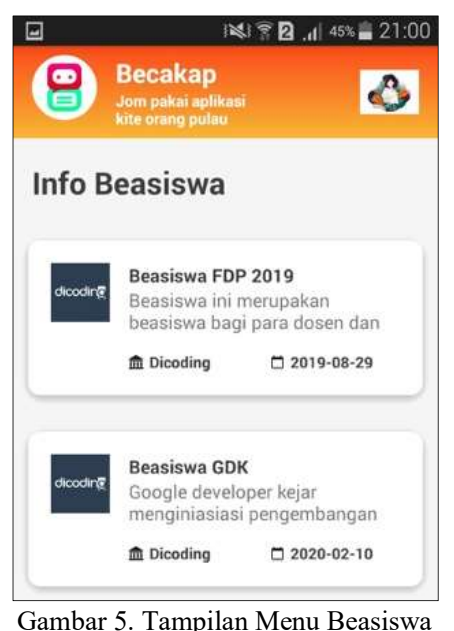

Gambar 5 menunjukkan tampilan menu beasiswa, pada saat pengguna memilih menu beasiswa, maka akan terlihat tampilan seperti gambar di atas. Namun untuk mengakses lebih lanjut, pengguna akan diminta untuk login terlebih dahulu. Dari hasil observasi dan wawancara ditemukan bahwa banyak anak-anak usia sekolah di beberpa pulau tidak melanjutkan pendidikannya. Hal ini disebabkan oleh keterbatasn biaya. Mereka juga tidak mendapatkan informasi terkait beasiswa-beasiswa yang bisa diperoleh untuk terus melanjutkan pendidikannya. Dengan adanya fitur ini, diharapkan siswa/i yang berada di pulau lebih termotivasi untuk melanjutkan pendidikan ke jenjang yang lebih tinggi.

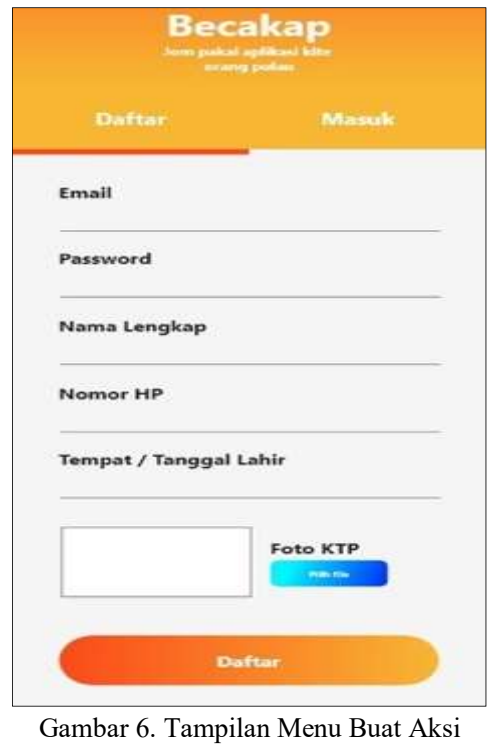

Gambar 6 menunjukkan tampilan menu buat aksi. Menu buat aksi ini diperuntukkan bagi pemuda/masyarakat pulau yang ingin mengajukan kegiatan yang akan dilaksanakan bersama-sama. Seperti misalnya membersihkan pantai. Menu ini memungkinkan pengguna menginformasikan aksi nya ke pengguna lainnya. Untuk dapat menggunakan menu ini, pengguna diminta untuk login terlebih dahulu. Menu Buat Aksi ini disajikan agar fungsi aplikasi sebagai media komunikasi tetap dapat difungsikan. Hal ini dapat menjadi daya tarik bagi masyarakat pesisir untuk menggunakan aplikasi ini. Dengan ada nya menu buat aksi, juga diharapkan dapat menjadi pemicu terjalinnya kolaborasi antar masyarakat pesisir.

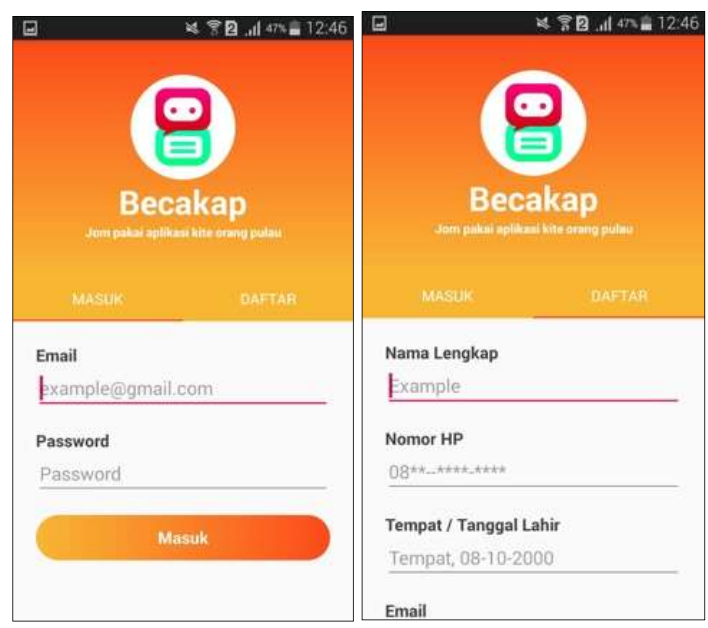

Gambar 7. Tampilan Menu Masuk dan Daftar 
Gambar 7 menunjukkan tampilan menu masuk. Menu masuk ini diperuntukkan pengguna yang ingin melihat informasi detail mengenai beasiswa dan juga membuat aksi. Sedangkan menu daftar adalah menu yang disediakan bagi pengguna untuk membuat akun.

\section{Tahapan Test dan Implement}

Tahapan Test dan Implement dilakukan dengan menguji cobakan fungsi-fungsi pada aplikasi tersebut oleh tim peneliti sebelum digunakan oleh masyarakat pesisir. Aplikasi Becakap yang dirancang ini juga disesuaikan dengan keadaaan masyarakat pesisir, tampilan aplikasi becakap dibuat seminimalis mungkin agar masyarakat pesisir mudah dalam menggunakannya. Selain itu, pemilihan warna juga disesuaikan dengan latar belakang budaya melayu yang dominan menggunakan warna merah, kuning, hijau. Hal lain yang diperhatikan dalam pembuatan aplikasi ini adalah ukuran aplikasi yang tergolong kecil yaitu $2.3 \mathrm{MB}$, hal ini dikarenakan keterbatasan spesifikasi smartphone yang dimiliki oleh masyarakat pesisir.

\section{KESIMPULAN}

Kesimpulan yang dapat ditarik dari pembahasan di atas adalah bahwa proses-proses di dalam design thinking seperti emphatize, define, ideate, prototype, test, dan implement dapat dimanfaatkan untuk menghasilkan prototype pengembangan aplikasi bagi masyarakat pesisir yang sesuai dengan kebutuhan masyarakat. Meskipun banyak aplikasi sejenis lainnya, namun dengan design thinking, pengembangan aplikasi lebih mengutamakan kebergunaan bagi pengguna.

\section{UCAPAN TERIMA KASIH}

Terima Kasih kepada Direktorat Riset dan Pengabdian Masyarakat, Direktorat Jenderal Penguatan Riset dan Pengembangan selaku pemberi dana melalui Hibah Program Penelitian Dosen Pemula tahun 2019.

\section{DAFTAR PUSTAKA}

[1] S. Amalina, F. Wahid, V. Satriadi, F. S. Farhani, and N. Setiani, 'Rancang Purwarupa Aplikasi UniBook Menggunakan Metode Pendekatan Design Thinking', Semin. Nas. Apl. Teknol. Inf. 2017 pp. 50-55, 2017

[2] A. Boediman and G. Morgen, Innofiction. PT.Elex Media Komputindo, 2018.

[3] T. Brown and J. Wyatt, 'Design Thinking for Social Innovation', Stanford Soc. Innov. Rev., vol. Winter, no. Winter 2010, pp. 30-35, 2010

[4] S. N. Qodriyatun, 'Peningkatan Kesejahteraan Masyarakat Pesisir Di Kota Batam Melalui Pemberdayaan Masyarakat', Aspirasi, vol. 4, no. 2, 2013 .

[5] N. Z. Janah, Y. Rokhayati, D. E. Kurniawan, and M. F. Muvariz, 'Electronic School Books Dissemination Application for Batam Hinterland Schools', Adv. Sci. Lett., vol. 24, no. 12, pp. 97399744, 2018.

[6] D. E. Kurniawan, N. Z. Janah, A. Wibowo, M. K. Mufida, and P. Prasetyawan, ' $\mathrm{C} 2 \mathrm{C}$ marketplace model in fishery product trading application using SMS gateway’, MATEC Web Conf., vol. 197,
2018

[7] C. Meinel and L. Leifer, 'Design Thinking Research', pp. 1-11, 2015.

[8] M. Dolata and G. Schwabe, 'Design Thinking in IS Research Projects', Des. Think. Innov., pp. 67-83, 2016.

[9] P. Prud 'homme Van Reine, 'The culture of design thinking for innovation', J. Innov. Manag. Prud'hom. van Reine JIM, vol. 5, no. 2, pp. 56-80, 2017.

[10] D. McDonagh and J. Thomas, 'Rethinking design thinking: Empathy supporting innovation', Australas. Med. J., vol. 3, no. 8, pp. 458-464, 2010

[11] K. O'Driscoll, 'The agile data modelling \& design thinking approach to information system requirements analysis', J. Decis. Syst., vol. 25, no. June, pp. 632-638, 2016.

[12] E. Ko and C. Meinel, 'Design Thinking Research', pp. 15-28, 2015 .

[13] K. Tschimmel, 'Design Thinking as an effective Toolkit for Innovation', ... XXIII ISPIM Conf. Action Innov. ..., no. June, pp. 1-20, 2012

[14] R. Razzouk and V. Shute, 'What Is Design Thinking and Why Is It Important?', Rev. Educ. Res., vol. 82, no. 3, pp. 330-348, 2012.

[15] F. Hager, T. Kowark, J. Kru, C. Vetterli, and M. Uflacker, 'DT@Scrum: Integrating Design Thinking with Software Development Processes', Des. Think. Res.,pp. 263-289, 2015. 